\title{
Prediabetes and Risk of Glomerular Hyperfiltration and Albuminuria in the General Non-Diabetic Population: A prospective Cohort Study
}

Toralf Melsom MD PhD ${ }^{1,3}$, Jørgen Schei MD ${ }^{1,4}$, Vidar Tor Nyborg Stefansson MD ${ }^{1}$, Marit Dahl Solbu MD PhD ${ }^{1,3}$, Trond Geir Jenssen MD $\mathrm{PhD}^{1,5}$, Ulla Dorte Mathisen $\mathrm{MD} \mathrm{PhD}^{1}$, Tom Wilsgaard $\mathrm{PhD}^{2}$ and Bjørn Odvar Eriksen $\mathrm{MD} \mathrm{PhD}^{1,3,4}$

${ }^{1}$ Metabolic and Renal Research Group, ${ }^{2}$ Dept. of Community Medicine, Faculty of Health Sciences, UiT The Arctic University of Norway; ${ }^{3}$ Section of Nephrology, ${ }^{4}$ Dept. of Clinical Research, University Hospital of North Norway, Tromsø; ${ }^{5}$ Oslo University Hospital, Oslo, Norway

Running title: Prediabetes, hyperfiltration and albuminuria

Word count abstract: 300

Word count text: 3463

Number of tables and figures: 4 tables and 3 figures (+ 1 supplemental figure and 3 supplemental tables)

Key words: Prediabetes, hyperfiltration, albuminuria, iohexol clearance, measured GFR, estimated GFR, fasting glucose, HbA1c, albumin-creatinine-ratio, ACR.

Corresponding author: Toralf Melsom, MD PhD

Section of Nephrology, University Hospital of North Norway

N-9038 Tromsø, Norway; email: toralf.melsom@unn.no

Phone: +47 77626511 


\begin{abstract}
Background: The role of prediabetes as a risk factor for hyperfiltration and albuminuria in persons who do not develop diabetes is unclear. The lack of evidence is mainly due to the difficulty of accurately assessing the glomerular filtration rate (GFR) in the near normal range of GFR. We investigated whether prediabetes is an independent risk factor for hyperfiltration and high normal urinary albumin-creatinine ratio (ACR) using measured GFR (mGFR) rather than estimated GFR.
\end{abstract}

Study Design: Prospective cohort study based on the Renal Iohexol Clearance Survey in Tromsø 6 (RENIS-T6) and the RENIS-Follow-Up. The median observation time was 5.6 years.

Setting \& Participants: A representative sample of 1261 persons without diabetes from the general population aged 50-62 years.

Predictor: Prediabetes defined by fasting glucose and $\mathrm{HbA}_{1 \mathrm{c}}$ according to the levels suggested by the American Diabetes Association (prediabetes.ADA.) and the International Expert Committee of 2009 (prediabetes IEC $_{\text {). }}$

Outcomes: Change in mGFR, hyperfiltration defined as mGFR $>90^{\text {th }}$. percentile adjusted for age, gender, weight and height, and high normal ACR (ACR > $10 \mathrm{mg} / \mathrm{g}$ ) at follow-up.

Measurements: GFR was measured with iohexol clearance.

Results: Baseline fasting glucose, $\mathrm{HbA}_{1 \mathrm{c}}$, and both definitions of prediabetes were predictors of a higher mGFR at follow-up and of a lower annual mGFR decline in multivariable-adjusted regression analyses. Participants with prediabetes IEC $_{\text {. }}$ had an odds ratio (95\% CI) of 
hyperfiltration of 1.95 (1.20-3.17) and high normal ACR of 1.83 (1.04-3.22) at follow-up. We adjusted for cardiovascular risk factors including ambulatory blood pressure at baseline and change in use of anti-hypertensive medication between baseline and follow-up.

Limitations: Only middle-aged Caucasians participated. There is no consensus on how to define glomerular hyperfiltration.

Conclusions: Our findings imply an independent role of prediabetes in development of hyperfiltration and albuminuria. Prediabetes might be a target for early treatment to prevent chronic kidney disease in chronic hyperglycemia.

Diabetes-related kidney disease accounts for almost 50\% of patients with end-stage renal disease in the developed world. ${ }^{1}$ Even with optimal treatment of new-onset diabetes, a large percentage of patients will develop chronic kidney disease (CKD). Prediabetes is approximately twice as common as diabetes, affecting $20-35 \%$ of adults, and it progresses to diabetes in $45-50 \%$ of individuals after 10 years. ${ }^{2,3}$ Prediabetes has been associated with CKD in cross-sectional studies, ${ }^{4,5}$ but whether prediabetes predicts CKD in persons who do not develop diabetes is unclear. Longitudinal studies did not find prediabetes to be an independent risk factor for albuminuria or incident CKD, defined as an estimated GFR $<60 \mathrm{ml} / \mathrm{min} / 1.73$ $\mathrm{m}^{2}{ }^{6-11}$ If prediabetes is a causal factor in the development of kidney disease, this condition would represent a window of opportunity to treat kidney damage at an early and reversible stage.

Recently, we reported that prediabetes, defined as impaired fasting glucose, was associated with an abnormally high GFR, or glomerular hyperfiltration, in a cross-sectional study of the 
general population. ${ }^{12}$ Glomerular hyperfiltration has been established as an early manifestation of diabetic nephropathy and has been shown to predict albuminuria and GFR decline in diabetes. ${ }^{13,14}$ Hyperfiltration is also a possible common causal pathway for other causes of CKD; however, the longitudinal association between prediabetes and hyperfiltration remains to be established. Previous longitudinal studies assessing the association between prediabetes and kidney function used estimated GFR (eGFR) to assess changes in GFR. eGFR has low precision, particularly in the higher range of GFR, ${ }^{15}$ and is expected to have low sensitivity for detecting hyperfiltration and GFR changes in the normal range. eGFR is also biased by non-GFR-related factors such as obesity, smoking, hyperglycemia and nontraditional cardiovascular risk factors. ${ }^{16-18}$

We hypothesized that prediabetes is a risk factor for renal hyperfiltration and high normal ACR during an intermediate follow-up time point. To overcome the limitations of using eGFR, we measured GFR (mGFR) by iohexol clearance at baseline in 2007-2009 and at follow-up in 2013-2015 in a general population cohort without self-reported diabetes, cardiovascular disease (CVD) or kidney disease at baseline. To study the independent role of prediabetes, we excluded persons diagnosed with diabetes at baseline and at follow-up.

\section{RESEARCH DESIGN AND METHODS}

\section{Study participants}

The Renal Iohexol Clearance Survey in Tromsø 6 (RENIS-T6) was conducted from October 2007 to September 2009 as a sub-study of the population-based sixth Tromsø study (Tromsø 6) in the municipality of Tromsø, northern Norway. ${ }^{19}$ The RENIS-T6 included a representative sample of 1627 persons aged 50-62 years from the general population without self-reported kidney disease, myocardial infarction, stroke or diabetes. A description of the 
study participants and enrollment in the RENIS-T6 is shown in Figure 1 and has been previously published in detail. ${ }^{19}$

The RENIS Follow-Up Study (RENIS-FU) was conducted from September 2013 to January 2015. Seven persons had a possible adverse reaction to iohexol in the RENIS-T6, and 23 persons died during the follow-up period. The remaining 1597 participants were invited to RENIS-FU, and 1368 (86\%) gave a positive response, but 39 did not make their appointments and 5 subjects could not be examined because the antecubital vein could not be cannulated. Accordingly, a total of 1324 (83\%) patients were examined in RENIS-FU (Figure 1). In the present investigation, an additional 25 persons with diabetes (fasting glucose $>=126 \mathrm{mg} / \mathrm{dL}$ $(7.0 \mathrm{mmol} / \mathrm{l})$ and/or glycosylated hemoglobin $\left.\left(\mathrm{HbA}_{1 \mathrm{c}}\right)>=6.5 \%\right)$ at baseline were excluded. The study was approved by the Norwegian Data Inspectorate and the Regional Ethics Committee of Northern Norway (2012/122/REK nord). All subjects provided written informed consent.

\section{Data Collection and Measurements}

Both RENIS-T6 and RENIS-FU were conducted at the Clinical Research Unit at the University Hospital of Northern Norway with a standardized procedure and the same staff responsible for all measurements. Participants met between 8:00 and 10:00 a.m. after an overnight fast, including abstinence from tobacco.

\section{Iohexol clearance}

GFR was measured at baseline and follow-up using single-sample plasma clearance of iohexol. Participants were instructed to avoid large meals with meat and non-steroid antiinflammatory drugs during the 2 days prior to the investigation. A Teflon catheter was placed in an antecubital vein. Five milliliters of iohexol (Omnipaque, $300 \mathrm{mg} / \mathrm{ml}$, Amersham Health, 
London, U.K.) was injected, and the syringe was weighed before and after injection. The venous catheter was flushed with $30 \mathrm{ml}$ of isotonic saline. After a calculated time period based on each person's estimated GFR, the iohexol blood sample was drawn from the same catheter. The serum iohexol concentration was measured by high-performance liquid chromatography, as described by Nilsson-Ehle. ${ }^{20}$ The analytical coefficient of variation during the study period was 3\% in RENIS-T6 and 3.1\% in RENIS-FU. To explore the possibility of a drift in the method between baseline and follow-up we reanalyzed iohexol and recalculated mGFR in a random sample of 105 serum samples frozen at $-80^{\circ} \mathrm{C}$ at baseline. There was a mean difference of $2.28 \mathrm{ml} / \mathrm{min} / 1.73 \mathrm{~m}^{2}$ between the original baseline measure and the repeated baseline measure taken from the thawed sample. An adjustment was made by adding this difference to the baseline measurements. mGFR was calculated as described by

Jacobsson. ${ }^{21}$ Details regarding the iohexol clearance measurements are published elsewhere. ${ }^{19}$

\section{Other measurements including albumin-creatinine ratio (ACR)}

Serum creatinine analyses were performed using a standardized enzymatic assay, and cystatin C was measured by particle-enhanced turbidimetric immunoassay as previously described. ${ }^{18}$ GFR was estimated from creatinine or cystatin C using the Chronic Kidney Disease Epidemiology Collaboration (CKD-EPI). ${ }^{15}$

Three samples of first-void morning spot urine were collected on separate days at baseline and at follow-up. Urinary albumin excretion and urinary creatinine were measured with commercial kits as described previously. ${ }^{22}$ The albumin-creatinine ratio (ACR) in mg/mmol was calculated for each urine-specimen, and the mean ACR value was used in the analyses. High normal ACR was defined as ACR $>10 \mathrm{mg} / \mathrm{g}(>1.13 \mathrm{mg} / \mathrm{mmol})$ as suggested by the CKD Prognosis Consortium because this level has been associated with increased risks of CVD, CKD and mortality. ${ }^{23,24}$ 
$\mathrm{HbA}_{1 \mathrm{c}}$ was measured using liquid chromatography (Variant II instrument, Bio-Rad Laboratories, Hercules, CA, USA), and fasting serum glucose was measured on the Modular model P800 (Roche Diagnostics). The insulin samples were measured with an ELISA kit (DRG Instruments, Marburg, Germany) as previously reported. ${ }^{12}$

Ambulatory blood pressure (aBP) recordings were started after the baseline iohexol clearance measurement (RENIS-T6) and continued for 24 hours; the method is described in a previous publication. $^{25}$

\section{Definition of prediabetes and hyperfiltration}

We defined prediabetes according to fasting glucose (FG) and $\mathrm{HbA}_{1 \mathrm{c}}$ to capture both fasting hyperglycemia and part of non-fasting hyperglycemia, both of which may represent distinct pathophysiological abnormalities. ${ }^{2}$ Prediabetes was defined as FG 110-125 mg/dL (6.1-6.9 $\mathrm{mmol} / \mathrm{l})$ and/or $\mathrm{HbA}_{1 \mathrm{c}}$ 6.0-6.4\% according to the classification of "high risk state of developing diabetes” by the International Expert Committee of 2009 (prediabetes IEC $_{\text {) }}$ or as FG 100-125 mg/dL (5.6-6.9 mmol/l) and/or $\mathrm{HbA}_{1 \mathrm{c}}$ 5.7-6.4\% according to the American Diabetes Association criteria (prediabetes.ADA.). ${ }^{26,27}$ In addition we made a separate group for those with

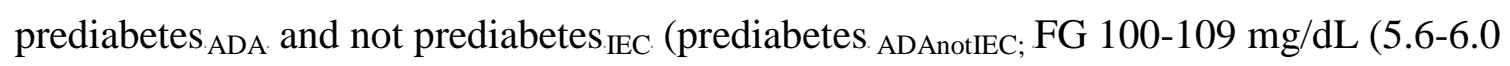
$\mathrm{mmol} / \mathrm{l})$ and/or $\mathrm{HbA}_{1 \mathrm{c}}$ 5.7-5.9\%). Diabetes was defined as $\mathrm{FG} \geq 126 \mathrm{mg} / \mathrm{dL}(7.0 \mathrm{mmol} / \mathrm{l})$ or $\mathrm{HbA}_{1 \mathrm{C}} \geq 6.5 \%$ or the use of anti-diabetic medication or self-reported diabetes. Normoglycemia was defined as FG $<100 \mathrm{mg} / \mathrm{dL}(5.6 \mathrm{mmol} / \mathrm{l})$ and $\mathrm{HbA}_{1 \mathrm{C}}<5.7 \%$.

Glomerular hyperfiltration was defined as an absolute GFR above the $90^{\text {th }}$ percentile after adjusting for gender, age, weight and height, as previously described. ${ }^{12}$ 
Information regarding health status, medications, smoking status and physical exercise were obtained using a questionnaire. Smoking status was divided into current smokers and nonsmokers. Physically active participants were defined as those performing hard physical exercise for $>1 \mathrm{~h} / \mathrm{wk}$ and/or light physical exercise for $>3 \mathrm{~h} / \mathrm{wk} .{ }^{16}$ Obesity was defined as body mass index (BMI) $\geq 30 \mathrm{~kg} / \mathrm{m}^{2}$.

\section{Statistical analysis}

Mean (SD) or median (IQR) values (for skewed distributions) were calculated for participants by glycemic groups at baseline. Linear trends across the three groups; normoglycemia,

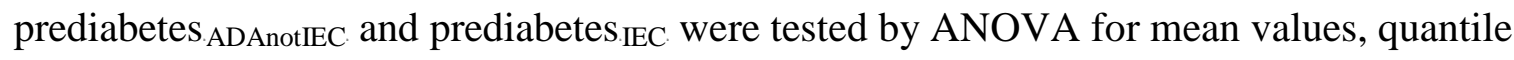
regression for median values and logistic regression for dichotomous variables.

The associations between baseline fasting glucose (FG), $\mathrm{HbA}_{1 \mathrm{c}}$, prediabetes and mGFR expressed in $\mathrm{ml} / \mathrm{min} / 1.73 \mathrm{~m}^{2}$ and as $\mathrm{ml} / \mathrm{min}$ at follow-up were assessed by multiple linear regression analysis. We adjusted for the following known or possible confounders: in model 1, we adjusted for age, gender and baseline use angiotensin converting enzyme inhibitors (ACEi) or angiotensin receptor blockers (ARB); in model 2, we also adjusted for BMI, smoking, daytime systolic aBP, fasting insulin levels, physical exercise and ACR; and in model 3, we adjusted for all of the preceding covariates, as well as baseline mGFR and change in use of antihypertensive medication and change in FG from baseline to follow-up.

Predictors of annual change in absolute $\mathrm{mGFR}(\Delta \mathrm{GFRa}$ in $\mathrm{ml} / \mathrm{min} /$ year) were analyzed with $\triangle \mathrm{GFRa}$ as the dependent variable and using the same independent and adjusting variables as described above, including an adjustment for baseline mGFR in all of the models. In these analyses, we also adjusted for a change in body weight because body weight is correlated with 
absolute GFR (model 3). $\Delta$ GFRa was calculated by subtracting mGFR (ml/min) at baseline from mGFR (ml/min) at follow-up and dividing the difference by follow-up time in years.

To investigate a possible non-linear association between FG or $\mathrm{HbA}_{1 \mathrm{c}}$ and $\Delta \mathrm{GFRa}$ or mGFR at follow-up, we used multiple fractional polynomial regression analyses, adjusting for the same variables as in model 3 of the linear regression analyses.

Multiple logistic regression models were used to determine the odds ratios for hyperfiltration, mGFR $<60 \mathrm{ml} / \mathrm{min} / 1.73 \mathrm{~m}^{2}$ or ACR $>10 \mathrm{mg} / \mathrm{g}(>1.1 \mathrm{mg} / \mathrm{mmol})$ at follow-up associated with baseline FG, $\mathrm{HbA}_{1 \mathrm{c}}$ and prediabetes status, adjusted for the same variables described in the 3 models above. (In model 3 with ACR $>10 \mathrm{mg} / \mathrm{g}$ at follow-up as dependent variable we adjusted for baseline ACR instead of baseline mGFR). We tested for interactions between all independent variables and gender in all of the linear and logistic regression models.

Stata software version 13 (Stata Corp., College Station, Texas, USA) was used for statistical analysis. Statistical significance was set at $P<0.05$.

\section{RESULTS}

Thirty-eight individuals had diabetes at follow-up (RENIS-FU); these persons were excluded. Accordingly, 1261 non-diabetic persons with a GFR measurement at baseline and at followup remained for analyses (Figure 1). The median (interquartile range) observation time was 5.6 years $(5.2-6.0)$.

Comparisons of the baseline characteristic of those included in the follow-up study $(\mathrm{N}=1299)$ and those lost to follow-up ( $\mathrm{N}=295)$ are shown in Supplemental Table 1. Except for the percentage of current smokers (18 vs. $28, \mathrm{p}<0.001)$, the differences were small. 
A total of 595 participants had prediabetes.ADA (FG 5.6-6.9 mmol/l and/or $\mathrm{HbA}_{\text {1c }}$ 5.7-6.4\%),

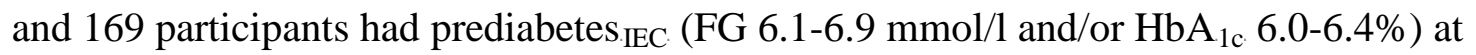
baseline. Baseline characteristics of the participants by glycemic status and in total are shown in Table 1. Age, night-time systolic aBP, BMI, insulin levels and triglyceride levels increased across the prediabetic groups while HDL-cholesterol levels, the proportion of females and the proportion performing physical exercise decreased across the groups. Baseline mGFR, but not eGFR from creatinine or cystatin C, was higher in the prediabetic groups. The distribution of mGFR and ACR (log-transformed) at baseline, and of change in mGFR and ACR (logtransformed) between baseline and follow-up is shown in Figure 2.

\section{The association between baseline glycemic status and mGFR at follow-up}

Higher baseline FG and $\mathrm{HbA}_{1 \mathrm{c}}$ values and prediabetes according to either definition were associated with a higher mGFR at follow-up, adjusted for age, sex and use of ACE-i or ARB, systolic aBP, BMI, smoking status, fasting insulin levels, physical exercise and ACR (Table 2, model 2). One percentage unit higher $\mathrm{HbA}_{1 \mathrm{c}}$ at baseline was associated with a 3.8 $\mathrm{ml} / \mathrm{min} / 1.73 \mathrm{~m}^{2}$ (95\% CI, 1.4-6.1) higher mGFR at follow-up. FG, $\mathrm{HbA}_{1 \mathrm{c}}$ and prediabetes IEC, $_{\text {, }}$ but not prediabetes.ADA, remained predictors of an increased mGFR after adjusting for baseline mGFR, change in glucose and change in anti-hypertensive medication from baseline to follow-up (model 3). Similar results but with larger estimates were obtained when we used absolute GFR at follow up (without BSA indexing) as dependent variable (Supplemental Table 2)

The mean annual change in $\mathrm{mGFR}(\Delta \mathrm{GFRa}$ in $\mathrm{ml} / \mathrm{min} /$ year) was -1.0 (95\% CI: -1.1 to -0.9 ) $\mathrm{ml} / \mathrm{min} /$ year for persons without prediabetes and -0.7 (95\% CI: -1.0 to 0.4 ) $\mathrm{ml} / \mathrm{min} /$ year for

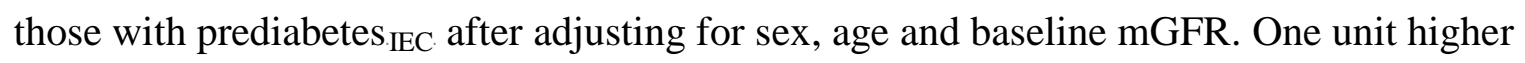
baseline FG and $\mathrm{HbA}_{1 \mathrm{c}}$ values were associated with a 0.39 (95\% CI: 0.08-0.69) $\mathrm{ml} / \mathrm{min} /$ year 
and 0.40 (95\% CI: 0.04-0.76) ml/min/year slower mGFR decline (higher $\Delta$ GFRa), respectively, in the multivariable adjusted regression model (Figure 3 and Supplemental Table $3)$.

There were no significant non-linear associations between FG or $\mathrm{HbA}_{1 \mathrm{c}}$ and $\Delta \mathrm{GFRa}$ or mGFR at follow-up (Supplemental Figure 1a and 1b).

\section{Glycemic status and odds ratio for hyperfiltration, CKD and high normal ACR}

The adjusted odds ratios for incident hyperfiltration and for CKD, defined as mGFR $<60$ $\mathrm{ml} / \mathrm{min} / 1.73 \mathrm{~m}^{2}$ at follow-up, are shown in Table 3. Higher baseline FG and $\mathrm{HbA}_{1 \mathrm{c}}$ values and prediabetes $_{\text {IEC }}$ at baseline were associated with increased odds of hyperfiltration at follow-up

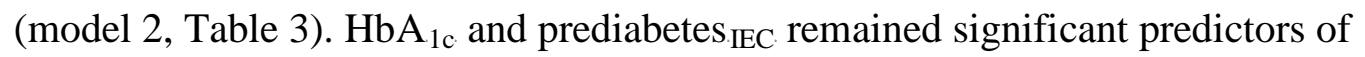
hyperfiltration after an additional adjustment for baseline hyperfiltration status (model 3).

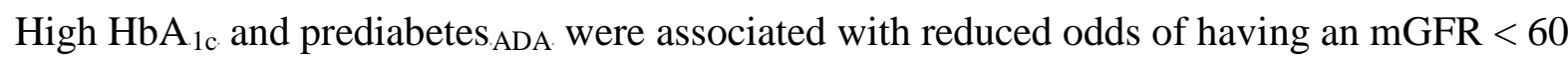
$\mathrm{ml} / \mathrm{min} / 1.73 \mathrm{~m}^{2}$ at follow-up in all models.

Eighty-eight persons had an ACR > $10 \mathrm{mg} / \mathrm{g}$ at follow-up. High baseline FG and prediabetes $_{\text {IEC }}$, but not $\mathrm{HbA}_{1 \mathrm{c}}$ and prediabetes ${ }_{\mathrm{ADA}}$, were associated with an increased odds for high normal ACR (Table 4). Baseline FG remained a significant predictor of high normal

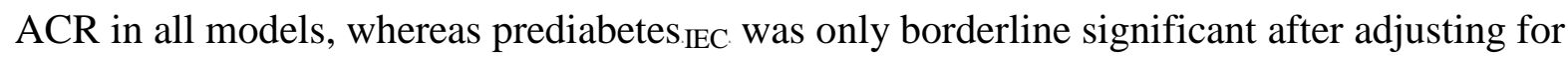
baseline ACR (model 3, Table 4). Persons with prediabetes defined by only an impaired fasting glucose (FG: 110-125 mg/dL) $(\mathrm{N}=75)$ had an OR of 3.2 (95\% CI: 1.4-7.3) for a high normal ACR in the fully adjusted model.

Finally, we repeated all main analyses after adjusting for night-time instead of daytime aBP and after including the 38 persons with diabetes at follow-up. The results were essentially similar as in table 2, 3 and 4 . The results were also similar without adjustment for the 2.28 
$\mathrm{ml} / \mathrm{min} / 1.73 \mathrm{~m}^{2}$ drift in the method for iohexol clearance measurement between baseline and follow-up.

\section{DISCUSSION}

In this cohort from a general middle-aged population without diabetes, we found that different measures of borderline hyperglycemia were predictors of higher mGFR and hyperfiltration after nearly 6 years follow up. FG and prediabetes IEC $_{\text {. were also risk factors for increased }}$ ACR.

To our knowledge, no prior study of the general population has assessed the longitudinal association between prediabetes and mGFR. In a study of Pima Indians, Nelson et al. found that $\mathrm{mGFR}$ (given as absolute GFR in $\mathrm{ml} / \mathrm{min}$ ) increased during 4 years follow up in 28 persons with an impaired glucose tolerance at baseline. ${ }^{28}$ However, the mean baseline BMI in these individuals was $39 \mathrm{~kg} / \mathrm{m}^{2}$, and the increase in mGFR was most prominent in the 12 persons who developed diabetes at follow-up. ${ }^{28}$ Moreover, the results were not statistically significant when the change in mGFR was scaled by body surface area $\left(\mathrm{ml} / \mathrm{min} / 1.73 \mathrm{~m}^{2}\right) .{ }^{29}$

Several previous population-based studies with 4-8 years of follow up reported that prediabetes did not predict CKD or decreased GFR when using eGFR after adjusting for cardiovascular risk factors. ${ }^{6-9}$ Schottker et al. concluded that prediabetes is not a likely a cause for the development of kidney disease. ${ }^{7}$ In contrast, we found that prediabetes predicted higher mGFR and hyperfiltration after almost six years of follow up. If hyperfiltration in prediabetes represents a maladaptive response to metabolic changes, as indicated by animal models and in studies of patients with diabetes, ${ }^{13,14,30}$ the process of kidney damage is likely to start early in the course of chronic hyperglycemia. The current finding of an increased risk 


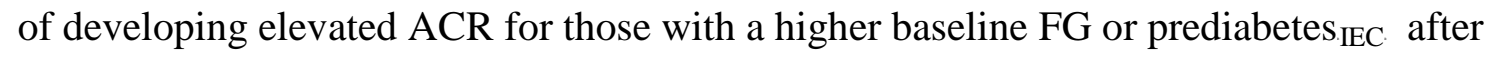
excluding persons with diabetes at baseline and follow-up supports this theory.

Hyperfiltration combined with hyperglycemia has been found to induce podocyte stress, podocyte injury, and cell apoptosis in animal models. ${ }^{31}$ However, it remains unclear whether hyperfiltration itself is harmful and what the long-term consequences of hyperfiltration are in prediabetes. We did not find that prediabetes increased the odds ratio of having a mGFR $<60$ $\mathrm{ml} / \mathrm{min} / 1.73 \mathrm{~m}^{2}$ after 5.6 years. In contrast, $\mathrm{HbA}_{1 \mathrm{c}}$ and prediabetes ${ }_{\mathrm{ADA}}$. were associated with a reduced risk of $\mathrm{mGFR}<60 \mathrm{ml} / \mathrm{min} / 1.73 \mathrm{~m}^{2}$, most likely due to the hyperfiltration effect (Table 3). A study of mGFR with a longer follow up time is needed to address whether hyperfiltration in prediabetes predicts overt CKD. Interestingly, a meta-analysis of diabetesrelated hyperfiltration studies that used mGFR, and also a recent prospective study of mGFR in 600 hypertensive patients with type 2 diabetes, found an increased hazard ratio of developing diabetes nephropathy in those with hyperfiltration at baseline. ${ }^{13,32}$ However, hyperfiltration did not predict diabetes nephropathy in studies that estimated the GFR by creatinine or cystatin C. ${ }^{33,34}$ Compared to persons with normoglycemia, our study found a significantly higher mGFR, but not a higher eGFRcre or eGFRcys, in persons with prediabetes at baseline. This difference may be due to the low precision of the equations used to estimate GFR in the normal range of GFR. Furthermore, it has recently been shown that risk factors such as fasting glucose, obesity and smoking, as well as non-traditional CVD risk factors, influence cystatin C- and creatinine-based eGFR after accounting for mGFR. ${ }^{16-18}$ Accordingly, eGFR should not be used in studies of hyperfiltration and may also be inadequate in examining the association between glucose and early GFR decline. Furthermore, the current finding of a longitudinal association between borderline 
hyperglycemia and increased mGFR or hyperfiltration has consequences for the use of GFR decline rate as an outcome in observational studies and clinical trials.

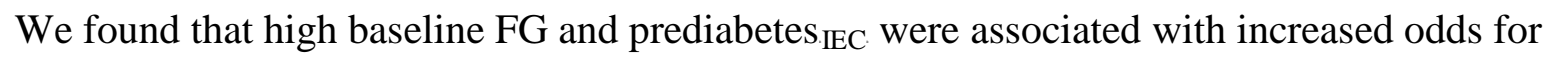
high normal ACR. A few longitudinal investigations have reported the association between prediabetes or non-diabetic hyperglycemia and the risk of albuminuria; the results are conflicting. ${ }^{9,10,35}$ Most of these studies did not adjust for other cardiovascular risk factors, but in two population-based studies in persons without diabetes, increased FG in men and HbA $\mathrm{Ac}_{1 \mathrm{c}}$ in both genders were found to be independent predictors of increased urinary albumin excretion. ${ }^{22,36}$ However, neither of these studies excluded persons with diabetes at follow-up. Because elevated ACR may be a result of hypertension and early nephropathy, we adjusted for baseline ambulatory BP, use of antihypertensive medication and change in antihypertensive medication during follow-up, and obtained similar results. We also adjusted for fasting insulin levels because reduced insulin sensitivity has been associated with greater risk of albuminuria. ${ }^{37}$ Our results are noteworthy because ACR $>10 \mathrm{mg} / \mathrm{g}$ has been found to predict CVD, CKD and death in general-population cohorts. ${ }^{23,24}$ Importantly, potential interventions like diet and physical activity promotion programs in prediabetes have been shown to reduces glucose levels. ${ }^{38}$ Furthermore, physical exercise have been shown to reduce the odds ratio of hyperfiltration and to modify the effect of fasting glucose on GFR. ${ }^{39}$ In addition, new treatment options in hyperglycemia like the Sodium/Glucose Cotransporter 2 (SGLT2) inhibitors may prevent hyperfiltration independently of the glucose lowering effect. ${ }^{40}$ However, a possible renoprotective effect of physical exercise and SGLT2 inhibition needs to been confirmed.

Our study has some limitations, including the following: only middle-aged Caucasians participated, limiting generalizability to other groups; furthermore, we did not perform a 
glucose tolerance test to assess non-fasting hyperglycemia. However, we combined fasting glucose and $\mathrm{HbA}_{1 \mathrm{c}}$ and used accepted definitions of prediabetes. ${ }^{26,27}$ There is no consensus on how to define glomerular hyperfiltration in population studies. Hyperfiltration at a whole kidney level is likely to reflect hyperfiltration at the glomerular level, but is also influenced by the number of nephrons. Since nephron numbers varies between individuals and by sex and age, we used an adjusted definition of hyperfiltration as reported in detail previously. ${ }^{12}$

A major strength of this study is that GFR was measured by iohexol clearance at baseline and follow-up in a large cohort from the general population. To our knowledge, RENIS is the only longitudinal study measuring GFR in the general population. FG and $\mathrm{HbA}_{1 \mathrm{c}}$ were measured twice, and we excluded those persons who developed diabetes at follow-up. Urine was collected on three separate days both at baseline and at follow-up, and albumin and creatinine were assessed in unfrozen specimens. Finally, we were able to control for several possible confounders, including ambulatory BP at baseline and changes in antihypertensive medication during follow-up.

In conclusion, we found that prediabetes was an independent risk factor for hyperfiltration and increased ACR during 5.6 years follow up in a representative cohort of the general population. Our findings suggest an independent role of prediabetes in CKD development and may in part explain the negative results of previous longitudinal studies of prediabetes that defined CKD based on eGFR only. Studies with longer follow up times, preferably with measured GFR and/or with albuminuria as outcomes, are needed to establish whether nondiabetic hyperglycemia is an independent predictor of CKD. If so, prediabetes might be a target for early treatment to prevent the increasing burden of CKD in diabetes. 


\section{ACKNOWLEDGMENTS}

We would like to thank Britt-Ann Winter Eilertsen, Bjørg Skog Høgset, Saskia van Heusden, and the rest of the staff at the Clinical Research Unit, University Hospital of North Norway (UNN), for their assistance in planning the study, performing the procedures, and collecting data according to the GCP standard. We also thank Harald Strand and the staff at the Department of Laboratory Medicine (UNN) for HPLC analyses of iohexol, and Inger Sperstad and Ingrid Dorthea Sandstad (Clinical Research Centre, UNN) for database support.

Contributions: research idea and study design: BOE, TM, UDM; data acquisition: BOE, TM, UDM, JS; data analysis/interpretation: TM, BOE, JS, VTNS, MDS, TW; statistical analysis: TM, BOE, TW; supervision or mentorship: BOE, TGJ, MDS. Each author contributed important intellectual content during manuscript drafting or revision and accepts accountability for the overall work by ensuring that questions pertaining to the accuracy or integrity of any portion of the work are appropriately investigated and resolved. TM and BOE take responsibility that this study has been reported honestly, accurately, and transparently; that no important aspects of the study have been omitted, and that any discrepancies from the study as planned have been explained.

\section{Support and Financial Disclosure Declaration}

The RENIS-FU was funded by the Northern Norway Regional Health Authority (SFP 110013) with additional grants from Boehringer-Ingelheim (1235.104 IIS). The funders did not have any role in study design; collection, analysis, and interpretation of data; writing the report; and the decision to submit the report for publication. None of the authors have declared any other conflicts of interest. 


\section{REFERENCES:}

1. Tuttle KR, Bakris GL, Bilous RW, et al. Diabetic kidney disease: a report from an ADA Consensus Conference. Am J Kidney Dis. Oct 2014;64(4):510-533.

2. Tabak AG, Herder C, Rathmann W, Brunner EJ, Kivimaki M. Prediabetes: a high-risk state for diabetes development. Lancet. Jun 16 2012;379(9833):2279-2290.

3. Morris $\mathrm{DH}$, Khunti $\mathrm{K}$, Achana F, et al. Progression rates from HbA1c $6.0-6.4 \%$ and other prediabetes definitions to type 2 diabetes: a meta-analysis. Diabetologia. Jul 2013;56(7):1489-1493.

4. Zhou Y, Echouffo-Tcheugui JB, Gu JJ, et al. Prevalence of chronic kidney disease across levels of glycemia among adults in Pudong New Area, Shanghai, China. BMC Nephrol. 2013;14:253.

5. Plantinga LC, Crews DC, Coresh J, et al. Prevalence of chronic kidney disease in US adults with undiagnosed diabetes or prediabetes. Clin.J.Am.Soc.Nephrol. 4/2010 2010;5(4):673-682.

6. Fox CS, Larson MG, Leip EP, Meigs JB, Wilson PW, Levy D. Glycemic status and development of kidney disease: the Framingham Heart Study. Diabetes Care. 10/2005 2005;28(10):24362440.

7. Schottker B, Brenner H, Koenig W, Muller H, Rothenbacher D. Prognostic association of $\mathrm{HbA1c}$ and fasting plasma glucose with reduced kidney function in subjects with and without diabetes mellitus. Results from a population-based cohort study from Germany. Preventive medicine. Nov 2013;57(5):596-600.

8. Selvin E, Ning Y, Steffes MW, et al. Glycated hemoglobin and the risk of kidney disease and retinopathy in adults with and without diabetes. Diabetes. Jan 2011;60(1):298-305.

9. Sun $F$, Tao $Q$, Zhan S. Metabolic syndrome and the development of chronic kidney disease among 118924 non-diabetic Taiwanese in a retrospective cohort. Nephrology (Carlton, Vic.). Feb 2010;15(1):84-92.

10. Lucove J, Vupputuri S, Heiss G, North K, Russell M. Metabolic syndrome and the development of CKD in American Indians: the Strong Heart Study. Am J Kidney Dis. Jan 2008;51(1):21-28.

11. Tozawa M, Iseki C, Tokashiki K, et al. Metabolic syndrome and risk of developing chronic kidney disease in Japanese adults. Hypertens Res. Oct 2007;30(10):937-943.

12. Melsom T, Mathisen UD, Ingebretsen OC, et al. Impaired fasting glucose is associated with renal hyperfiltration in the general population. Diabetes Care. 7/2011 2011;34(7):1546-1551.

13. Magee GM, Bilous RW, Cardwell CR, Hunter SJ, Kee F, Fogarty DG. Is hyperfiltration associated with the future risk of developing diabetic nephropathy? A meta-analysis. Diabetologia. 4/2009 2009;52(4):691-697.

14. Moriya T, Tsuchiya A, Okizaki SI, Hayashi A, Tanaka K, Shichiri M. Glomerular hyperfiltration and increased glomerular filtration surface are associated with renal function decline in normo- and microalbuminuric type 2 diabetes. Kidney Int. 12/7/2011 2011.

15. Inker $\mathrm{LA}$, Schmid $\mathrm{CH}$, Tighiouart $\mathrm{H}$, et al. Estimating glomerular filtration rate from serum creatinine and cystatin C. N.Engl.J.Med. 7/5/2012 2012;367(1):20-29.

16. Mathisen UD, Melsom T, Ingebretsen OC, et al. Estimated GFR Associates with Cardiovascular Risk Factors Independently of Measured GFR. J.Am.Soc.Nephrol. 5/2011 2011;22(5):927-937.

17. Rule AD, Bailey KR, Lieske JC, Peyser PA, Turner ST. Estimating the glomerular filtration rate from serum creatinine is better than from cystatin $C$ for evaluating risk factors associated with chronic kidney disease. Kidney Int. 6/2013 2013;83(6):1169-1176.

18. Melsom T, Fuskevag OM, Mathisen UD, et al. Estimated GFR Is Biased by Non-Traditional Cardiovascular Risk Factors. Am J Nephrol. 2015;41(1):7-15. 
19. Eriksen BO, Mathisen UD, Melsom T, et al. Cystatin C is not a better estimator of GFR than plasma creatinine in the general population. Kidney Int. 12/2010 2010;78(12):1305-1311.

20. Nilsson-Ehle P. Iohexol clearance for the determination of glomerular filtration rate: 15 years' experience in clinical practice. eJIFCC. 2006 2006;13(2).

21. Jacobsson L. A method for the calculation of renal clearance based on a single plasma sample. Clin.Physiol. 8/1983 1983;3(4):297-305.

22. Solbu MD, Kronborg J, Eriksen BO, Jenssen TG, Toft I. Cardiovascular risk-factors predict progression of urinary albumin-excretion in a general, non-diabetic population: a genderspecific follow-up study. Atherosclerosis. 12/2008 2008;201(2):398-406.

23. Levey AS, de Jong PE, Coresh J, et al. The definition, classification, and prognosis of chronic kidney disease: a KDIGO Controversies Conference report. Kidney Int. Jul 2011;80(1):17-28.

24. Matsushita K, van der Velde M, Astor BC, et al. Association of estimated glomerular filtration rate and albuminuria with all-cause and cardiovascular mortality in general population cohorts: a collaborative meta-analysis. Lancet. Jun 12 2010;375(9731):2073-2081.

25. Mathisen UD, Melsom T, Ingebretsen OC, et al. Ambulatory blood pressure is associated with measured glomerular filtration rate in the general middle-aged population. Journal of hypertension. Mar 2012;30(3):497-504.

26. Nathan D. International Expert Committee report on the role of the A1C assay in the diagnosis of diabetes. Diabetes Care. 7/2009 2009;32(7):1327-1334.

27. American Diabetes Association. Diagnosis and classification of diabetes mellitus. Diabetes Care. Jan 2014;37 Suppl 1:S81-90.

28. Nelson RG, Bennett PH, Beck GJ, et al. Development and progression of renal disease in Pima Indians with non-insulin-dependent diabetes mellitus. Diabetic Renal Disease Study Group. N.Engl.J.Med. 11/28/1996 1996;335(22):1636-1642.

29. Nelson RG, Tan $M$, Beck GJ, et al. Changing glomerular filtration with progression from impaired glucose tolerance to Type II diabetes mellitus. Diabetologia. 1/1999 1999;42(1):9093.

30. Kriz W, Lemley KV. A Potential Role for Mechanical Forces in the Detachment of Podocytes and the Progression of CKD. Journal of the American Society of Nephrology. February 1, 2015 2015;26(2):258-269.

31. Lewko B, Stepinski J. Hyperglycemia and mechanical stress: targeting the renal podocyte. J.Cell Physiol. 11/2009 2009;221(2):288-295.

32. Ruggenenti P, Porrini EL, Gaspari F, et al. Glomerular Hyperfiltration and Renal Disease Progression in Type 2 Diabetes. Diabetes Care. 7/6/2012 2012.

33. Ficociello LH, Perkins BA, Roshan B, et al. Renal hyperfiltration and the development of microalbuminuria in type 1 diabetes. Diabetes Care. 5/2009 2009;32(5):889-893.

34. Thomas MC, Moran JL, Harjutsalo V, et al. Hyperfiltration in type 1 diabetes: does it exist and does it matter for nephropathy? Diabetologia. 5/2012 2012;55(5):1505-1513.

35. Watanabe H, Obata H, Watanabe T, Sasaki S, Nagai K, Aizawa Y. Metabolic syndrome and risk of development of chronic kidney disease: the Niigata preventive medicine study.

Diabetes/metabolism research and reviews. Jan 2010;26(1):26-32.

36. Brantsma AH, Atthobari J, Bakker SJ, De Zeeuw D, de Jong PE, Gansevoort RT. What predicts progression and regression of urinary albumin excretion in the nondiabetic population? J.Am.Soc.Nephrol. 2/2007 2007;18(2):637-645.

37. Pilz S, Rutters F, Nijpels G, et al. Insulin Sensitivity and Albuminuria: The RISC Study. Diabetes Care. June 1, 2014 2014;37(6):1597-1603.

38. Balk EM, Earley A, Raman G, Avendano EA, Pittas AG, Remington PL. Combined Diet and Physical Activity Promotion Programs to Prevent Type 2 Diabetes Among Persons at Increased Risk: A Systematic Review for the Community Preventive Services Task Force. Ann Intern Med. Jul 142015. 
39. Melsom T, Mathisen UD, Eilertsen BAW, et al. Physical Exercise, Fasting Glucose, and Renal Hyperfiltration in the General Population: The Renal lohexol Clearance Survey in Troms $\varnothing 6$ (RENIS-T6). Clinical Journal of the American Society of Nephrology. 11/7/2012 2012;7(11):1801-1810.

40. De Nicola L, Gabbai FB, Liberti ME, Sagliocca A, Conte G, Minutolo R. Sodium/Glucose Cotransporter 2 Inhibitors and Prevention of Diabetic Nephropathy: Targeting the Renal Tubule in Diabetes. American Journal of Kidney Diseases. (0). 
Table 1. Baseline characteristics of participants by glycemic status

Please see enclosed table 1 on separate page.

Table 2. The association between glycemic variables and mGFR at follow-up analyzed by multiple linear regression

\begin{tabular}{|c|c|c|c|c|c|c|c|c|c|}
\hline & \multicolumn{3}{|c|}{ Model 1} & \multicolumn{3}{|c|}{ Model 2} & \multicolumn{3}{|c|}{ Model 3} \\
\hline & $(\mathrm{ml} / \mathrm{min} /$ & & & $(\mathrm{ml} / \mathrm{min} /$ & & & $(\mathrm{ml} / \mathrm{min} /$ & & \\
\hline & $\left.1.73 \mathrm{~m}^{2}\right)$ & $95 \%$ & $\mathrm{CI}$ & $\left.1.73 \mathrm{~m}^{2}\right)$ & $95 \%$ & CI & $\left.1.73 \mathrm{~m}^{2}\right)$ & $95 \%$ & $\mathrm{CI}$ \\
\hline Baseline fasting glucose, per mmol/L & 2.93 & $(1.27$ & $-4.60)$ & 3.71 & $(1.90$ & $-5.52)$ & 1.89 & $(0.36$ & $-3.41)$ \\
\hline Baseline Hba1c, per \% unit & 3.77 & $(1.51$ & $-6.02)$ & 3.78 & $(1.43$ & $-6.13)$ & 2.14 & $(0.36$ & $-3.92)$ \\
\hline Prediabetes $_{\mathrm{ADA}}$ at baseline, yes/no & 2.42 & $(0.94$ & - 3.90$)$ & 2.57 & $(1.04$ & $-4.10)$ & 0.90 & $(-0.27$ & $-2.06)$ \\
\hline Prediabetes $_{\text {IEC }}$ at baseline, yes/no & 3.36 & $(1.21$ & $-5.52)$ & 3.49 & $(1.28$ & $-5.71)$ & 2.24 & $(0.56$ & $-3.92)$ \\
\hline Mean fasting glucose*, per mmol/L & 4.14 & $(2.34$ & - 5.94) & 5.24 & (3.27 & $-7.22)$ & 2.04 & $(0.53$ & $-3.56)$ \\
\hline Mean HbA1ct, per \% unit & 4.34 & (1.76 & - 6.91) & 4.36 & (1.66 & - 7.01) & 2.38 & $(0.34$ & $-4.43)$ \\
\hline
\end{tabular}

Abbreviations: mGFR, measured GFR; ADA, American Diabetes Association, IEC, International Expert Committee of 2009. Model 1: Adjusted for baseline age, sex and baseline use of ACEi or Angiotensin receptor blocker (ARB). Model 2: As in model 1 and adjusted for baseline BMI, daytime systolic aBP, smoking, fasting insulin, physical exercise and ACR. Model 3: As in model 2 and adjusted for basline GFR, change in fasting glucose and use of antihypertensive medication including ACEi or ARB from baseline to follow-up. *Mean fasting glucose: (baseline FG + FG at follow up)/2. Estimate in model 3; not adjusted for change in FG. † Mean HbA1c: (baseline HbA1c + HbA1c at follow up)/2. Estimate in model 3; not adjusted for change in FG. 
Table 3. Odds ratio (OR) for hyperfiltration and for $\mathrm{mGFR}<60 \mathrm{ml} / \mathrm{min} / 1.73 \mathrm{~m}^{2}$ at follow-up analyzed by multiple logistic regression

\begin{tabular}{|c|c|c|c|c|c|c|c|c|c|}
\hline & \multicolumn{3}{|c|}{ Model $1(N=1261)$} & \multicolumn{3}{|c|}{ Model $2(N=1252)$} & \multicolumn{3}{|c|}{ Model $3(N=1252)$} \\
\hline & OR & $95 \%$ & CI & OR & $95 \%$ & CI & OR & $95 \%$ & CI \\
\hline \multicolumn{10}{|l|}{ OR for hyperfiltration ( $N=126)$ : } \\
\hline Baseline fasting glucose, per mmol/L & 1.79 & $(1.19$ & $-2.70)$ & 1.88 & $(1.20$ & 2.96) & 1.70 & $(0.98$ & $-2.96)$ \\
\hline Baseline Hba1c, per \% unit & 2.42 & $(1.33$ & $-4.40)$ & 2.27 & $(1.23$ & - 4.21$)$ & 2.25 & $(1.14$ & $-4.39)$ \\
\hline Prediabetes $_{\mathrm{ADA}}$ at baseline, yes/no & 1.47 & $(1.01$ & $-2.15)$ & 1.42 & $(0.96$ & $-2.10)$ & 1.30 & $(0.84$ & $-2.00)$ \\
\hline Prediabetes $_{\text {IEC }}$ at baseline, yes/no & 2.03 & $(1.27$ & $-3.25)$ & 1.95 & $(1.20$ & - 3.17$)$ & 1.79 & $(1.03$ & $-3.12)$ \\
\hline \multicolumn{10}{|c|}{ OR for $\mathrm{mGFR}<60 \mathrm{ml} / \mathrm{min} / 1.73 \mathrm{~m}^{2}$ (N=33): } \\
\hline Fasting glucose, per mmol/L & 0.41 & $(0.17$ & $-0.98)$ & 0.46 & $(0.18$ & $-1.20)$ & 0.71 & $(0.22$ & $-2.29)$ \\
\hline Hba1c, per \% unit & 0.25 & $(0.09$ & $-0.75)$ & 0.24 & $(0.08$ & - 0.78$)$ & 0.23 & $(0.06$ & $-0.92)$ \\
\hline Prediabetes $_{\mathrm{ADA}}$, yes/no & 0.25 & $(0.10$ & $-0.60)$ & 0.29 & $(0.12$ & - 0.71$)$ & 0.29 & $(0.10$ & $-0.79)$ \\
\hline Prediabetes $_{\mathrm{IEC}}$, yes/no & 0.39 & $(0.09$ & - 1.69) & 0.50 & $(0.11$ & $-\quad 2.27)$ & 0.53 & $(0.09$ & $-3.22)$ \\
\hline
\end{tabular}

Abbreviations: mGFR, measured GFR; ADA, American Diabetes Association, IEC, International Expert Committee of 2009. Model 1: Adjusted for baseline age, sex, and use of ACEi or Angiotensin receptor blocker (ARB). Model 2: As in model 1 and adjusted for baseline BMI, daytime systolic aBP, BMI, smoking, fasting insulin, physical exercise and ACR (9 missing values in total). Model 3: As in model 2 and adjusted for hyperfiltration status or GFR at baseline, change in fasting glucose and use of anti-hypertensive medication including ACEi or ARB from baseline to follow-up. 
Table 4. Odds ratios for high normal ACR* at follow-up analyzed by multiple logistic regression.

\begin{tabular}{|c|c|c|c|c|c|c|c|c|c|}
\hline \multirow[b]{2}{*}{ OR for high normal ACR* $(\mathrm{N}=88)$} & \multicolumn{3}{|c|}{ Model $1(\mathrm{~N}=1261)$} & \multicolumn{3}{|c|}{ Model $2(\mathrm{~N}=1256)$} & \multicolumn{3}{|c|}{ Model $3(\mathrm{~N}=1252)$} \\
\hline & OR & $95 \%$ & $\mathrm{CI}$ & OR & $95 \%$ & CI & OR & $95 \%$ & $\mathrm{CI}$ \\
\hline Baseline fasting glucose, per mmol/L & 1.91 & $(1.18$ & $-3.10)$ & 2.10 & $(1.20$ & $-3.54)$ & 2.20 & $(1.21$ & $-3.90)$ \\
\hline Baseline HbA1c, per \% unit & 0.88 & $(0.44$ & $-1.72)$ & 0.71 & $(0.36$ & $-\quad 1.43)$ & 0.66 & $(0.32$ & - 1.32) \\
\hline Prediabetes.ADA $_{\text {at baseline , yes/no }}$ & 1.39 & $(0.89$ & $-2.16)$ & 1.32 & $(0.84$ & $-\quad 2.09)$ & 1.24 & $(0.77$ & $-2.02)$ \\
\hline Prediabetes $_{\text {IEC }}$ at baseline, yes/no & 1.92 & $(1.11$ & $-\quad 3.32)$ & 1.83 & $(1.04$ & $-\quad 3.22)$ & 1.71 & $(0.93$ & $-3.16)$ \\
\hline
\end{tabular}

Abbreviations: ACR, albumin-creatinin ratio. ${ }^{*} A C R>1.1 \mathrm{mg} / \mathrm{mmol}$ ( $>10 \mathrm{mg} / \mathrm{g}$ ). Model 1: Adjusted for baseline age, sex, and use of ACEi or Angiotensin receptor blocker (ARB). Model 2: As in model 1 and adjusted for baseline BMI, daytime systolic aBP, smoking, fasting insulin and physical exercise (5 missing values in total). Model 3: As in model 2 and adjusted for ACR at baseline, and for change in fasting glucose and use of anti-hypertensive medication including ACEi or ARB from baseline to follow-up (9 missing values in total). 


\section{Titles and figure legends:}

Table 1. Baseline characteristics of participants by glycemic status

Table 2. The association between glycemic variables and mGFR at follow-up analyzed by multiple linear regression

Table 3. Odds ratio for hyperfiltration and for GFR $<60 \mathrm{ml} / \mathrm{min} / 1.73 \mathrm{~m}^{2}$ at follow-up analyzed by multiple logistic regression

Table 4. Odds ratios for high normal ACR* at follow-up analyzed by multiple logistic regression

Figure 1. Inclusion of subjects in the Renal Iohexol Clearance Survey in Tromsø 6 (RENIST6) and the follow-up study (RENIS-FU)

Figure 2. Frequency histogram of mGFR and log-transformed ACR at baseline, and of change in mGFR and ACR between baseline and follow-up. Change in mGFR: mGFR at follow-up mGFR at baseline. Change in ACR: log-transformed ACR at follow-up - log-transformed ACR at baseline.

Figure 3. The association between baseline fasting glucose (FG) and change in mGFR per year (ml/min/year). The marginal effect of FG on annual change in mGFR, adjusted for sex and baseline age, mGFR, use of ACEi or angiotensin receptor blocker (ARB), daytime ambulatory BP, BMI, smoking, fasting insulin, physical exercise, albumin-creatinine ratio and for change in FG and use of anti-hypertensive medication including ACEi or ARB from baseline to follow-up. Horizontal lines are 95\% confidence interval.

\section{Supplemental titles and figure legends}

Supplemental Table 1. Baseline characteristics of persons included in the follow-up study and those lost to follow-up.

Supplemental Table 2. The association between glycemic variables and absolute mGFR (not indexed by BSA) at follow-up analyzed by multiple linear regression. 
Supplemental Table 3. Associations between glycemic variables and annual change in mGFR analyzed by multiple linear regression.

Supplemental Figure 1. The associations between a) baseline fasting glucose and mGFR at follow-up and b) baseline HbA1c and mGFR at follow-up, by multiple fractional polynomials. Adjusted for sex and baseline age, use of ACEi or angiotensin receptor blocker (ARB), daytime ambulatory BP, BMI, smoking, fasting insulin, physical exercise, albumincreatinine ratio, mGFR and for change in fasting glucose and use of anti-hypertensive medication including ACEi or ARB from baseline to follow-up. 
Table 1. Baseline characteristics of participants by glycemic status

\begin{tabular}{|c|c|c|c|c|c|}
\hline & \multicolumn{2}{|c|}{ Prediabetes $_{\mathrm{ADA}}$} & \multicolumn{2}{|c|}{ Prediabetes $_{\text {IEC }}$} & \multirow{2}{*}{$\begin{array}{c}\text { Total } \\
(\mathrm{N}=1261)\end{array}$} \\
\hline & No $(\mathrm{N}=666)$ & Yes $(\mathrm{N}=595)$ & No $(\mathrm{N}=1092)$ & Yes $(\mathrm{N}=169)$ & \\
\hline Age (y) & $57.5 \pm 3.9$ & $58.5 \pm 3.8$ & $57.8 \pm 3.9$ & $58.9 \pm 3.6$ & $57.9 \pm 3.9$ \\
\hline Male (\%) & 42 & 58 & 47 & 64 & 50 \\
\hline Body mass index $\left(\mathrm{kg} / \mathrm{m}^{2}\right)$ & $26.3 \pm 3.6$ & $27.8 \pm 3.7$ & $26.7 \pm 3.7$ & $28.6 \pm 3.7$ & $27.0 \pm 3.7$ \\
\hline Obese (\%) & 14 & 26 & 18 & 33 & 20 \\
\hline Current smoking (\%) & 18 & 20 & 19 & 22 & 19 \\
\hline Daytime systolic aBP (mmHg) & $128.7 \pm 13.3$ & $130.7 \pm 12.6$ & $129.5 \pm 13.1$ & $130.8 \pm 12.7$ & $129.7 \pm 13.0$ \\
\hline Daytime diastolic aBP (mmHg) & $81.5 \pm 8.8$ & $82.6 \pm 8.7$ & $82.0 \pm 8.6$ & $82.1 \pm 9.5$ & $82.0 \pm 8.7$ \\
\hline Night-time systolic aBP (mmHg) & $109.7 \pm 12.8$ & $111.3 \pm 11.1$ & $110.2 \pm 12.1$ & $112.2 \pm 11.9$ & $110.5 \pm 12.1$ \\
\hline Night-time diastolic aBP (mmHg) & $65.7 \pm 8.7$ & $67.0 \pm 8.2$ & $66.2 \pm 8.4$ & $66.9 \pm 9.2$ & $66.3 \pm 8.5$ \\
\hline ACEi or ARB use (\%) & 8 & 11 & 9 & 12 & 10 \\
\hline Fasting glucose (mmol/L) & $5.1(4.9-5.3)$ & $5.6(5.3-5.9)$ & $5.2(5.0-5.5)$ & $5.9(5.4-6.2)$ & $5.3(5.0-5.6)$ \\
\hline Hemoglobin A1c level (\% unit) & $5.4(5.2-5.5)$ & $5.7(5.6-5.9)$ & $5.5(5.3-5.7)$ & $6.0(5.7-6.1)$ & $5.5(5.3-5.7)$ \\
\hline Triglycerides (mmol/L) & $1.0(0.7-1.3)$ & $1.1(0.8-1.5)$ & $1.0(0.7-1.4)$ & $1.2(0.8-1.7)$ & $1.0(0.7-1.4)$ \\
\hline HDL-Cholesterol (mmol/L) & $1.60 \pm 0.43$ & $1.49 \pm 0.40$ & $1.56 \pm 0.42$ & $1.44 \pm 0.38$ & $1.55 \pm 0.42$ \\
\hline Albumin-creatinine ratio (mg/mmol) & $0.20(0.10-0.52)$ & $0.23(0.10-0.53)$ & $0.21(0.10-0.52)$ & $0.25(0.10-0.54)$ & $0.22(0.10-0.52)$ \\
\hline Leisure time physical exercise (\%) & 49 & 41 & 47 & 36 & 45 \\
\hline Fasting insulin $(\mu \mathrm{U} / \mathrm{ml})$ & $7.5(5.3-10.4)$ & $9.4(6.7-13.7)$ & $8.0(5.9-11.3)$ & $10.1(7.0-15.7)$ & $8.3(6.1-12.0)$ \\
\hline $\mathrm{mGFR} \dagger\left(\mathrm{ml} / \mathrm{min} / 1.73 \mathrm{~m}^{2}\right)$ & $89.9 \pm 14.3$ & $92.9 \pm 13.9$ & $90.9 \pm 14.1$ & $93.9 \pm 14.4$ & $91.3 \pm 14.2$ \\
\hline eGFRcre $\ddagger\left(\mathrm{ml} / \mathrm{min} / 1.73 \mathrm{~m}^{2}\right)$ & $94.9 \pm 9.6$ & $94.7 \pm 9.1$ & $94.8 \pm 9.3$ & $94.7 \pm 9.7$ & $94.8 \pm 9.3$ \\
\hline eGFRcys $\neq\left(\mathrm{ml} / \mathrm{min} / 1.73 \mathrm{~m}^{2}\right)$ & $106.0 \pm 12.3$ & $105.5 \pm 11.8$ & $105.8 \pm 12.0$ & $105.2 \pm 12.9$ & $105.8 \pm 12.1$ \\
\hline eGFRcrecys $\ddagger\left(\mathrm{ml} / \mathrm{min} / 1.73 \mathrm{~m}^{2}\right)$ & $103.4 \pm 11.5$ & $102.8 \pm 10.7$ & $103.2 \pm 11.1$ & $102.8 \pm 12.0$ & $103.1 \pm 11.2$ \\
\hline
\end{tabular}

\begin{tabular}{|c|c|c|c|}
\hline $\begin{array}{l}\text { Normoglycemia } \\
\quad(\mathrm{N}=666) \\
\end{array}$ & $\begin{array}{c}\text { Prediabetes }_{\text {ADAnotIEC }} \\
(\mathrm{N}=426)\end{array}$ & $\begin{array}{c}\text { Prediabetes }_{\text {IEC }} \\
\quad(\mathrm{N}=169)\end{array}$ & P value* \\
\hline $57.5 \pm 3.9$ & $58.3 \pm 3.9$ & $58.9 \pm 3.6$ & $<0.001$ \\
\hline 42 & 55 & 64 & $<0.001$ \\
\hline $26.3 \pm 3.6$ & $27.5 \pm 3.7$ & $28.6 \pm 3.7$ & $<0.001$ \\
\hline 14 & 23 & 33 & $<0.001$ \\
\hline 18 & 19 & 22 & 0.3 \\
\hline $128.7 \pm 13.3$ & $130.7 \pm 12.6$ & $130.8 \pm 12.7$ & 0.06 \\
\hline $81.5 \pm 8.8$ & $82.8 \pm 8.3$ & $82.1 \pm 9.5$ & 0.4 \\
\hline $109.7 \pm 12.8$ & $111.0 \pm 10.8$ & $112.2 \pm 11.9$ & 0.02 \\
\hline $65.7 \pm 8.7$ & $67.0 \pm 7.8$ & $66.9 \pm 9.2$ & 0.1 \\
\hline 8 & 11 & 12 & 0.07 \\
\hline $5.1(4.9-5.3)$ & $5.6(5.2-5.8)$ & $5.9(5.4-6.2)$ & $<0.001$ \\
\hline $5.4(5.2-5.5)$ & 5.7 (5.5-5.8) & $6.0(5.7-6.1)$ & $<0.001$ \\
\hline $1.0(0.7-1.3)$ & $1.1(0.8-1.5)$ & $1.2(0.8-1.7)$ & $<0.001$ \\
\hline $1.60 \pm 0.43$ & $1.51 \pm 0.40$ & $1.44 \pm 0.38$ & $<0.001$ \\
\hline $0.20(0.10-0.52)$ & $0.21(0.10-0.51)$ & $0.25(0.10-0.54)$ & 0.3 \\
\hline 49 & 44 & 36 & 0.002 \\
\hline $7.5(5.3-10.4)$ & $9.2(6.7-13.1)$ & $10.1(7.0-15.7)$ & $<0.001$ \\
\hline $89.9 \pm 14.3$ & $92.5 \pm 13.8$ & $93.9 \pm 14.4$ & 0.001 \\
\hline $94.9 \pm 9.6$ & $94.6 \pm 8.8$ & $94.7 \pm 9.7$ & 0.8 \\
\hline $106.0 \pm 12.3$ & $105.6 \pm 11.4$ & $105.2 \pm 12.9$ & 0.5 \\
\hline $103.4 \pm 11.5$ & $102.8 \pm 10.2$ & $102.8 \pm 12.0$ & 0.6 \\
\hline
\end{tabular}


Abbreviations: aBP, ambulatory blood pressure; ARB, angiotensin receptor blocker; GFR, glomerular filtration rate. Data are as means (SD) or medians (interquartile range), in case of skewed data distribution. There were thirteen missing values for $\mathrm{aBP}$, for daytime systolic aBP these were replaced with office systolic BP.

Prediabetes $_{\text {ADA }}$; fasting glucose (FG) 5.6-6.9 mmol/L and/or HbA1c 5.7-6.4\%; according to American Diabetes Association. ${ }^{27}$ Prediabetes ${ }_{\text {IEC }}$; FG 6.1-6-9 mmol/L and/or HbA1c 6.0-6.4\%; according to the international expert committee of 2009. ${ }^{26}$. Prediabetes. ${ }_{\text {ADAnotIEC} \text {; prediabetes }}{ }_{\text {ADA }}$, but not including prediabetes ${ }_{\text {IEC }}$ (FG 5.6-6.0 mmol/L and/or HbA1c 5.7-5.9\%).

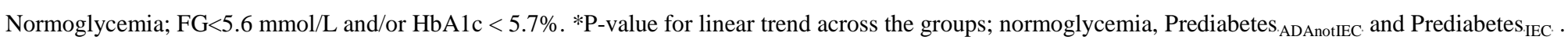

†GFR measured by single-sample iohexol clearance. ¥GFR estimated by the CKD-EPI equation based on creatinine, cystatin C or both. ${ }^{15}$

Conversion factors for units: Serum LDL-and HDL-cholesterol in mmol/L to mg/dL, /0.0259; serum triglycerides mmol/Lto mg/dL, /88.5; serum glucose mmol/l to mg/dL, /0.0555, urine albumin-creatinine ratio $\mathrm{mg} / \mathrm{mmol}$ to $\mathrm{mg} / \mathrm{g}$, /0.113. 


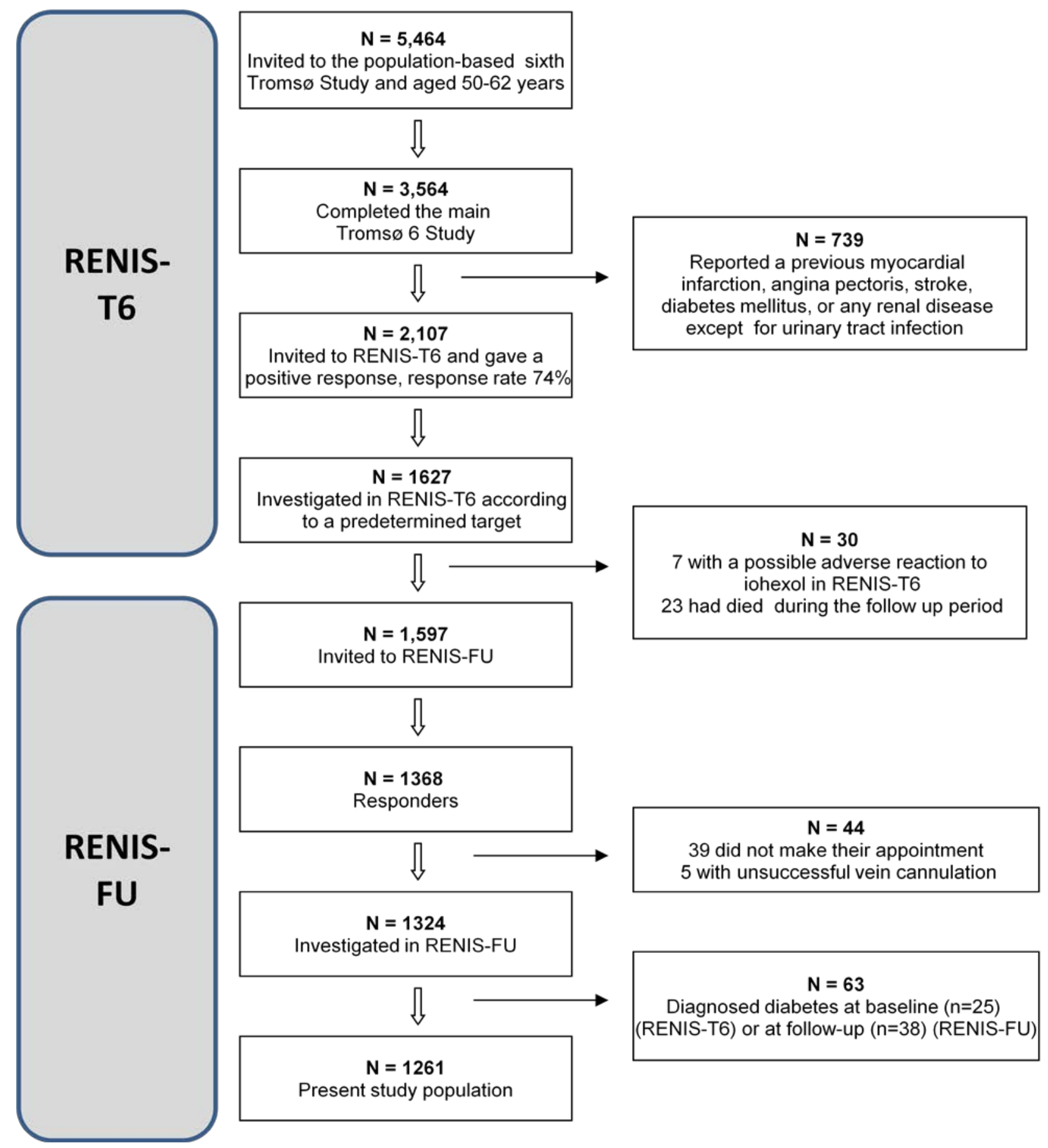



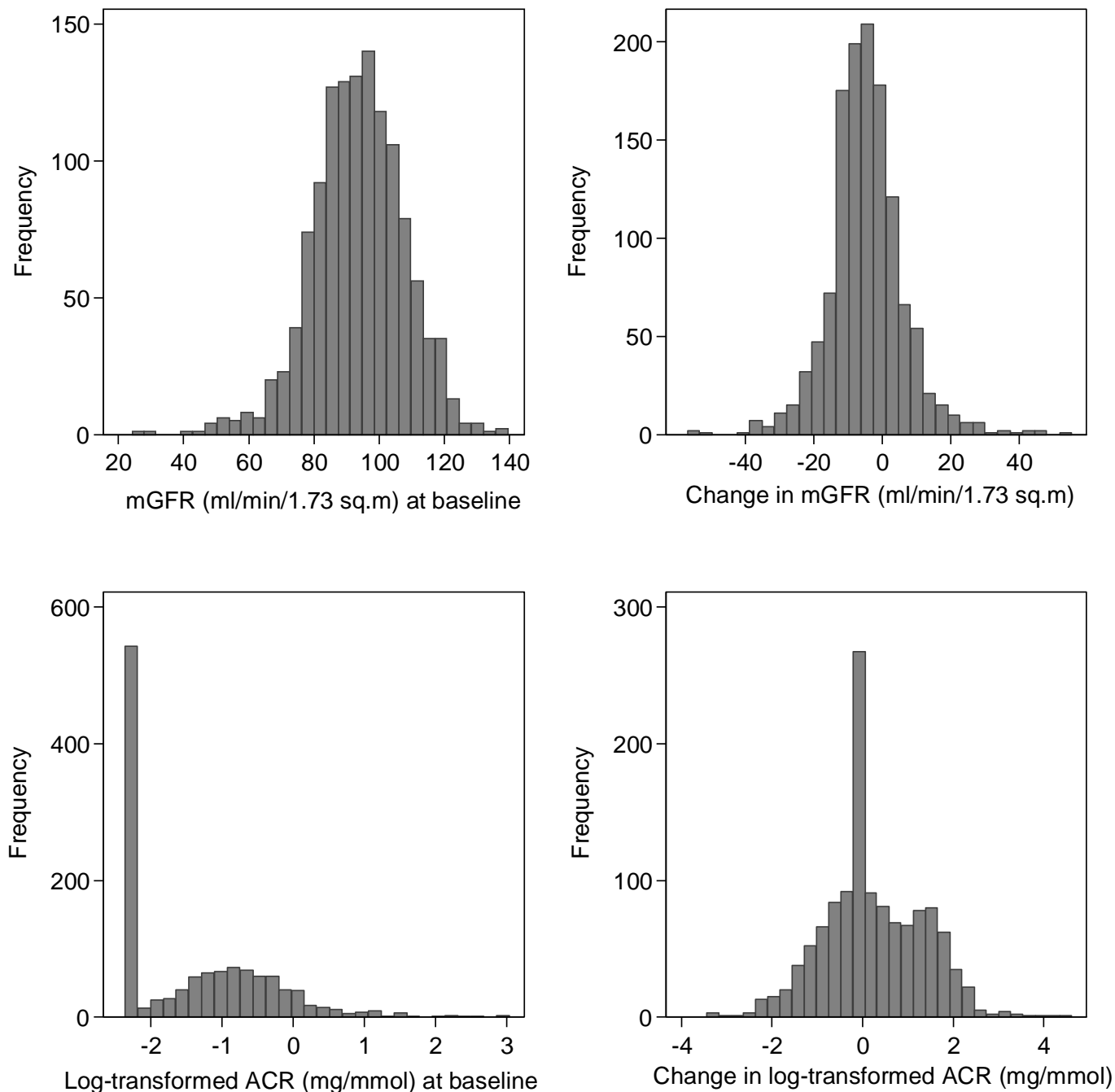

Figure 2 


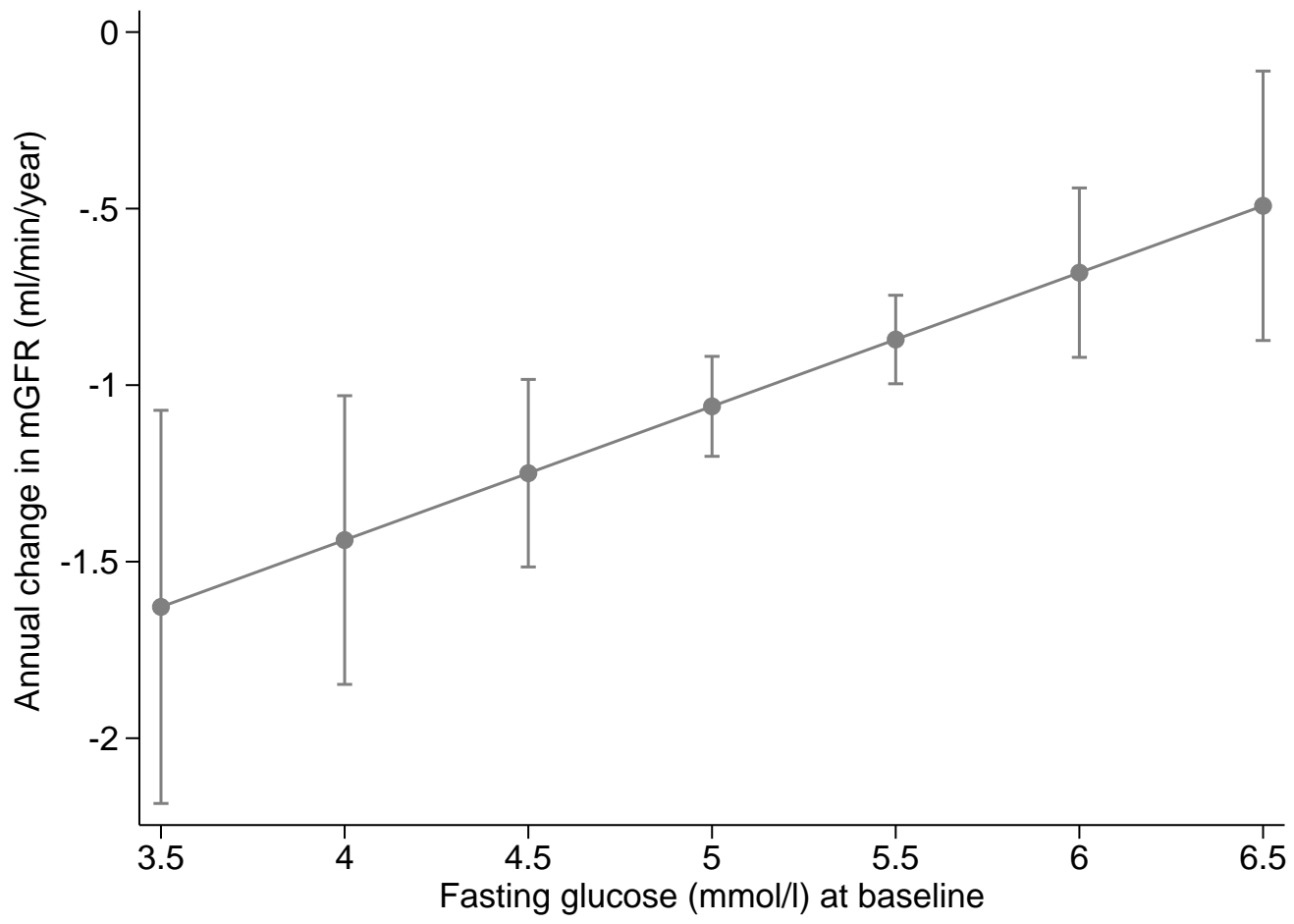



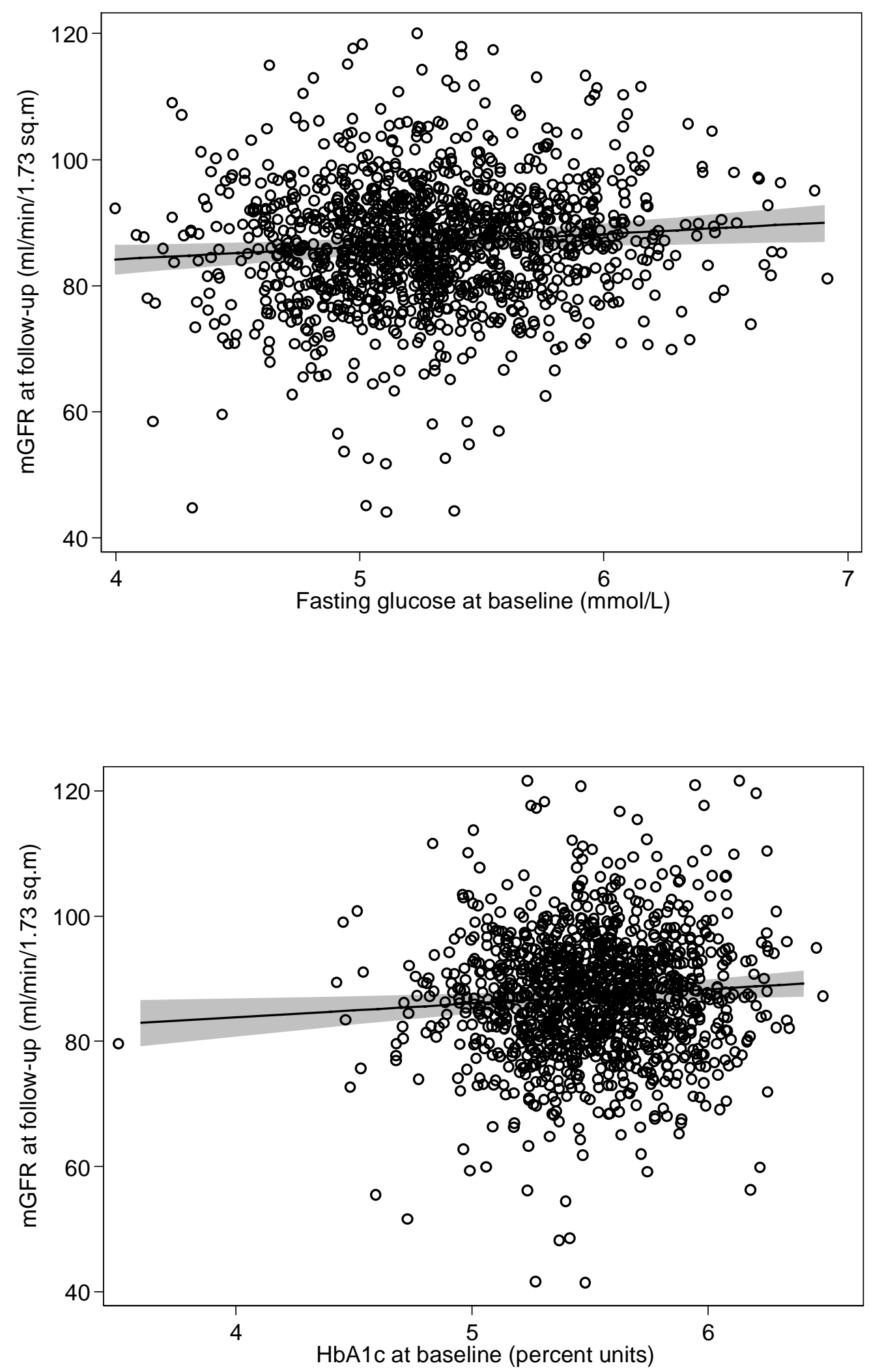

Supplemental Figure S1 a) and b) 
